\title{
Bismuth-based nanoparticles as radiosensitizer in low and high dose rate brachytherapy
}

\author{
Azimeh RAJAEE ${ }^{1, a}$ Shi WANG ${ }^{1}$, Lingyun ZHAO $^{2}$ \\ ${ }^{1}$ Institute of Medical Physics and Engineering, Department of Engineering Physics, Tsinghua University, Beijing 100084, \\ China \\ ${ }^{2}$ State Key Laboratory of New Ceramics and Fine Processing, School of Materials Science and Engineering, Tsinghua \\ University, Beijing 100084, China \\ ${ }^{a}$ E-mail address: rajaeea10@mails.tsinghua.edu.cn
}

(received 23 December 2018; revised 18 February 2019; accepted 11 April 2019)

\begin{abstract}
Background: Recently bismuth-based nanoparticles have attracted increasing attention as a dose amplification agent in radiation therapy due to high atomic number, high photoelectric absorption, low cost, and low toxicity.

Objectives: This study aims to calculate physical aspects of dose enhancement of bismuth-based nanoparticles in the presence of brachytherapy source by Monte Carlo simulation and an analytical method for low mono-energy.

Materials and methods: After simulation and validation brachytherapy sources (Iodine-125 and Ytterbium-169) by Monte Carlo code, bismuth-based nanoparticles (bismuth, bismuth oxide, bismuth sulfide, and bismuth ferrite) were modeled in the sizes of $50 \mathrm{~nm}$ and $100 \mathrm{~nm}$ for two concentrations of 10 and $20 \mathrm{mg} / \mathrm{ml}$. Dose enhancement factors for the bismuth-based nanoparticles were measured at both brachytherapy sources. Furthermore, the dose amplification was calculated with an analytic method at $30 \mathrm{keV}$ mono-energy.

Results: Dose enhancement factor was greatest with pure bismuth nanoparticles, followed by bismuth oxide, bismuth sulfide and bismuth ferrite for both radiation source and simulation methods. The dose amplification for the bismuthbased nanoparticles increased with increasing size and concentration of nanoparticles.

Conclusion: The physical aspect dose enhancement of the nanoparticles was shown by Monte Carlo and analytic method. The results have proved bismuth-based nanoparticles deserve further study as a radiosensitizer.
\end{abstract}

Key words: bismuth-based nanoparticles; brachytherapy source; radiosensitizer; Monte Carlo simulation; dose enhancement.

\section{Introduction}

Over the two last decades, extensive studies have been drawn on nanoparticles as a radiosensitizer in radiation therapy. Although radiation therapy is a well known noninvasive method in cancer therapy, we have faced serious limitation to protect the surrounding healthy tissue. This challenge could cause a serious problem, specifically for patients who prescribed to receive high radiation dose. To circumvent this restriction, nanoparticles (with a high atomic number) as radiosensitizer can be considered in the tumor. By adding the nanoparticles as a physical radiosensitizer to the tumor region, the local dose distribution increases around the nanoparticles compared to normal tissue due to the high absorption coefficient of the nanoparticles [1]. Radiosensitization mechanisms can be categorized into three items: physical, biological and chemical processes. From a physical point of view, high $\mathrm{Z}$ atomic number nanoparticles could enhance photoelectric interactions $\left(\sigma_{\mathrm{pe}} \sim \mathrm{Z}^{4} / \mathrm{E}^{3}\right.$, atomic number, $\mathrm{Z}$, the energy of a photon, E) and Auger electron in sub-MeV energies [2,3]. Therefore, nanoparticles have the significant ability on radiation dose amplification when kilovoltage energy such as brachytherapy source is applied [4,5]. Various kinds of high atomic number nanoparticles have been widely investigated as radiosensitizer such as gold, bismuth, platinum, tungsten, and gadolinium [6-8]. Although the most studies have been focused on gold nanoparticles, recently bismuth-based nanoparticles as a material with high atomic number $(Z=82)$, high photoelectric absorption, low cost, and low toxicity have been drawn considerable attention in radiotherapy [9-12]. For more than three centuries, bismuth metal compounds are extensively employed in medical applications. Compounds containing bismuth have been used for the treatment of gastroenterology illnesses, syphilis, skin lesions, and Helicobacter pylori infection [13,14].

In the size of nano, numerous studies (in vitro and in vivo experiments) have shown that bismuth-based nanoparticles

(c) 2019 Azimeh Rajaee, Shi Wang, Lingyun Zhao. This is an open access article licensed under the Creative Commons Attribution-NonCommercial-NoDerivs License (http://creativecommons.org/licenses/by-nc-nd/3.0/). 
could enhance the local dose within the tumor, thanks to their high X-ray attenuation coefficient. For example, uniform size bismuth nanoparticle (Bi) was prepared and investigated as computed tomography (CT) contrast agent for gastrointestinal tract imaging [15]. Moreover, the nanoparticles were detected as target tracing in CT/fluorescence imaging [16]. In the field of radiation therapy, the effect of bismuth nanoparticles on radiation dose enhancement was investigated for breast cancer [10]. Bismuth sulfide $\left(\mathrm{Bi}_{2} \mathrm{~S}_{3}\right)$ nanoparticles as a biocompatible bismuth-based radiosensitizer were introduced in imaging and radiation therapy [17]. In vitro and in vivo studies demonstrated that the $\mathrm{Bi}_{2} \mathrm{~S}_{3}$ nanoparticles have the ability to improve the efficacy of both radiation and photo-thermal therapy for cancer treatment [18,19]. The other kind of bismuth-based nanoparticles which was investigated as radiosensitizer is bismuth oxide nanoparticles $\left(\mathrm{Bi}_{2} \mathrm{O}_{3}\right)$. Results of the studies established the effect of $\mathrm{Bi}_{2} \mathrm{O}_{3}$ nanoparticles on radiation enhancement by clonogenic and modeling assays [20-22]. In our previous work, we confirmed the suitability of multifunction bismuth ferrite nanoparticles $\left(\mathrm{BiFeO}_{3}\right)$ as a magnetic local dose enhancement. Whereas bismuth ferrite has both dose amplification and magnetic property due to bismuth and iron elements, the nanoparticles were evaluated as a multimodal imaging contrast agent in magnetic resonance imaging (MRI) and computed tomography (CT) [6].

In this study, firstly, the Iodine-125 $\left({ }^{125} \mathrm{I}\right)$ as low dose rate (LDR) and Ytterbium-169 $\left({ }^{169} \mathrm{Yb}\right)$ as high dose rate (HDR) brachytherapy sources were simulated by Monte Carlo NParticle Transport (MCNP6) code. After validation of the radiation sources, radiation dose enhancement effect of the bismuth-based nanoparticles (bismuth, $\mathrm{Bi}$, bismuth oxide, $\mathrm{Bi}_{2} \mathrm{O}_{3}$, bismuth sulfide, $\mathrm{Bi}_{2} \mathrm{~S}_{3}$ and bismuth ferrite, $\mathrm{BiFeO}_{3}$ ) in presence of low dose rate (LDR) and high dose rate (HDR) brachytherapy sources was compared by MCNP6 code. Moreover, an analytic method [23] was considered to calculate second photoelectrons which are produced from interaction $\mathrm{X}$ ray with nanoparticles.

\section{Material and methods}

\section{Brachytherapy sources}

${ }^{125}$ I, SelectSeed 130.002 as low dose rate (LDR) and ${ }^{169} \mathrm{Yb}$, 4140 as high dose rate (HDR) brachytherapy sources were chosen from the studies by Karaiskos et al. [24] and Medich et al. [25], respectively. The geometry of the sources is illustrated in Figure 1a. The ${ }^{125} \mathrm{I}$ source consists of a cylinder rod with an outer diameter of $0.510 \mathrm{~mm}$ and a length of $3.40 \mathrm{~mm}$ which is covered with a silver halide layer $(\mathrm{AgCl} / \mathrm{AgI})$ in $3.00 \mu \mathrm{m}$ thick. Titanium capsule with hemisphere end shape (radius, $0.4 \mathrm{~mm}$ ) and length $4.5 \mathrm{~mm}$ is covered the active length of the source (3.40 mm).

High dose rate source $\left({ }^{169} \mathrm{Yb}\right)$ core is ytterbium oxide (6.9 $\mathrm{g} / \mathrm{cm}^{3}$ ) length $3.6 \mathrm{~mm}$ (active length) which is encapsulated by stainless steel with hemisphere shape in end (radius, $0.45 \mathrm{~mm}$ ) and length of $4.8 \mathrm{~mm}$. The stainless steel cable $\left(6.90 \mathrm{~g} / \mathrm{cm}^{3}\right)$ in the shape of a cylinder with a diameter of $0.9 \mathrm{~mm}$ and length $1.95 \mathrm{~mm}$ is attached in the source. Details dimension sources are mentioned in Figure 1a.

\section{Monte Carlo simulations}

\section{Calculation of TG-43 parameters}

High dose rate (HDR) and low dose rate (LDR) brachytherapy sources were modeled by general-purpose Monte Carlo NParticle Transport (MCNP6) code published by the Los Alamos National Laboratory. TG-43 parameters such as dose rate, air-kerma strength, dose rate constant, radial dose function, and anisotropy function in order to validate code were calculated from the below formula:

$\dot{D}(r, \theta)=S_{k} \Lambda \frac{G(r, \theta)}{G\left(r_{0}, \theta_{o}\right)} g(r) F(r, \theta)$

Eq 1.

$\dot{D}(r, \theta)$ is dose rate in distance $\mathrm{r}$, and polar angle $\theta$ from a line source in water. $S_{K}$ and $\Lambda$ denote air-kerma strength and dose rate constant, respectively. (a)

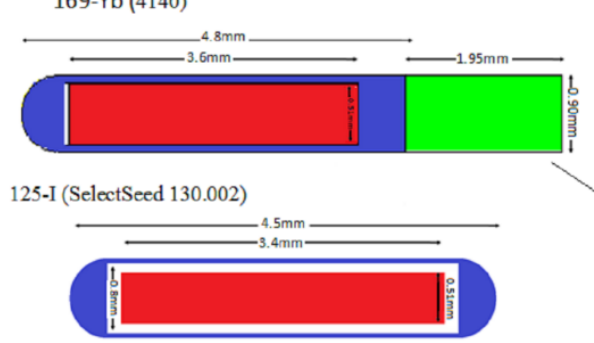

(b)

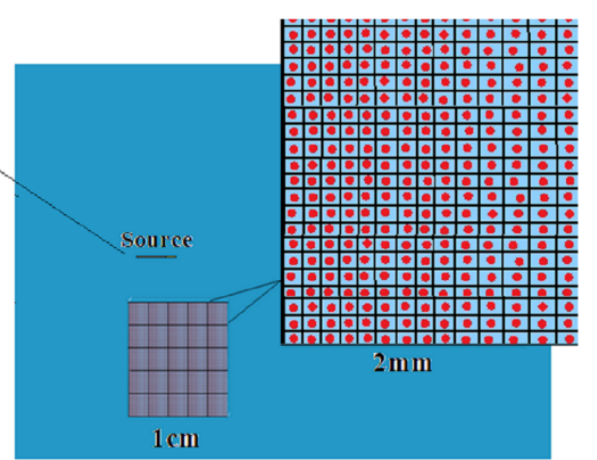

Figure 1. Schematic diagram of the 125I, SelectSeed 130.002 as low dose rate (LDR) and 169Yb, 4140 as high dose rate (HDR) brachytherapy sources (a). Diagram of modeling tumor cube and distribution of nanoparticles in the cube (b). 
Geometric factor, radial dose and the anisotropy function are calculated by the following equations.

$G(r, \theta)=r^{-2} \quad$ for the point source

Eq. 2

$G(r, \theta)=\frac{\beta}{L r \sin \theta}$

$\beta=\tan ^{-1}\left(\frac{r \sin \theta}{r \cos \theta-\frac{L}{2}}\right)-\tan ^{-1}\left(\frac{r \sin \theta}{r \cos \theta+\frac{L}{2}}\right)$

Eq. 4

$g(r)=\frac{\dot{D}\left(r, \theta_{0}\right)}{\dot{D}\left(r_{0}, \theta_{0}\right)} \frac{G_{L}\left(r_{0}, \theta_{0}\right)}{G_{L}\left(r, \theta_{0}\right)}$

$F(r, \theta)=\frac{\dot{D}(r, \theta)}{\dot{D}\left(r, \theta_{0}\right)} \frac{G_{L}\left(r, \theta_{0}\right)}{G_{L}(r, \theta)}$

Eq. 6

To calculate dose rate constant, $\Lambda$, for the ${ }^{169} \mathrm{Yb}$ source, dose distribution was measured in a voxel $(0$. ) which was centered on reference pint $\left(r=1, \frac{\theta}{2}\right)$ from a box phantom of water $\left(80 \times 80 \times 80 \mathrm{~cm}^{3}\right)$. Then it divided to air-kerma strength, $S_{K}$, which was calculated in voxels of $10 \times 10 \times 0.05 \mathrm{~cm}^{3}$ at distance $100 \mathrm{~cm}$ from the source center in vacuum. Dose rate constant $(\Lambda)$ for low dose rate (LDR) source, ${ }^{125} \mathrm{I}$, was calculated as we have done for high dose rate (HDR) source. However, in this case, reference point voxel was at a phantom water in size of $\left(30 \times 30 \times 30 \mathrm{~cm}^{3}\right)$. Dose rate distribution was calculated by F6 tally and cut off energy $2 \mathrm{keV}$ for ${ }^{125} \mathrm{I}$ and $10 \mathrm{keV}$ for ${ }^{169} \mathrm{Yb}$.

$S_{k}=\dot{K}_{\delta}(r) r^{2}$

where $\dot{K}_{\delta}(r)$ is air-kerma rate;

$\Lambda=\frac{\dot{D}\left(1 \mathrm{~cm}, \frac{\pi}{2}\right)}{S_{k}}$

Radiation sources were placed in a spherical water phantom to catch all scattering radiation and outside of sphere was void. Radial dose $g(r)$, and the anisotropy function $F(r, \theta)$ were calculated by detectors which were simulated as series of cones, centered in radiation sources with angles from $0^{\circ}$ to $180^{\circ}$ degree and radial distance from 1 to $10 \mathrm{~cm}$.

\section{Nanoparticles dose enhancement}

\section{MCNP-Monte Carlo}

Radiation sources $\left({ }^{125} \mathrm{I}\right.$ and $\left.{ }^{169} \mathrm{Yb}\right)$ were considered in center of sphere water phantom with radius $20 \mathrm{~cm}$ and a cubic tumor with a dimension of $1 \times 1 \times 1 \mathrm{~cm}^{3}$ was in $1 \mathrm{~cm}$ from the sources. The cube was divided into cells with a dimension of $2 \times 2 \times 2 \mathrm{~mm}^{3}$ and each cell was filled with smaller cells according to the concentration of nanoparticles (Figure 1b). Spherical nanoparticles in concentration $10 \mathrm{mg}$ and $20 \mathrm{mg}$ were placed in the smallest cells. Size of smallest cells for different kind of bismuth-based nanoparticles $\left(\mathrm{Bi}, \mathrm{Bi}_{2} \mathrm{O}_{3}, \mathrm{Bi}_{2} \mathrm{~S}_{3}\right.$, and $\mathrm{BiFeO}_{3}$ ) and concentration was changed. The number of nanoparticles were calculated according to concentration, density, and mass.

Dose distribution was calculated by F6 tally $(\mathrm{MeV} / \mathrm{g})$ in each $2 \times 2 \times 2 \mathrm{~mm}^{3}$ cells in the middle of the cube. Photon and electron cut off energy was $1 \mathrm{keV}$ (default of code) and simulation was performed for $10^{8}$ histories.

\section{Analytical simulation}

For analytical simulation according to previous works $[23,26,27]$ an endothelial cell (as a $10 \times 10 \times 2 \mu \mathrm{m}$ slab) and $\mathrm{X}$ ray radiation source at an energy of $30 \mathrm{keV}$ were considered. Bismuth-based nanoparticles $\left(\mathrm{Bi}, \mathrm{Bi}_{2} \mathrm{O}_{3}, \mathrm{Bi}_{2} \mathrm{~S}_{3}\right.$, and $\left.\mathrm{BiFeO}_{3}\right)$ at a various concentration $(10,20,30$ and $40 \mathrm{mg}$ ) were simulated. Dose enhancement effect of bismuth-based nanoparticles was calculated based on the equations presented at the previous works [23,26,27]. A based dose $D_{w}=2$ was chosen as dose absorbed in water cell without nanoparticles. Photon flux $(\Phi)$, the number of photons $\left(\mathrm{N}_{\mathrm{ph}}\right)$ incident on the nanoparticles and the probability $(\mathrm{P})$ of photoelectric interaction on nanoparticles are given by follow equations:

$\Phi=\frac{D_{w}}{E\left(\frac{\mu_{e n}}{\rho}\right)_{E}}$

Eq. 9

where $\Phi$ is photon flux, E is the energy of a photon, $\left(\frac{\mu_{e n}}{\rho}\right)$ is mass absorption coefficient of water at energy E;

$N_{p h}=\Phi \times \pi r^{2}$

Eq. 10

where $N_{p h}$ is the number of photons interacted by NPs and $\mathrm{r}$ is the radius of NPs;

$p \approx\left(\frac{\mu_{p e}}{\rho}\right)_{E} \times \rho_{N P} \times d_{N P}$

Eq. 11

where $\mathrm{p}$ is a probability of photoelectric interaction on nanoparticles, $\rho_{N P}$ is denthe sity of nanoparticles and $d_{N P}=\frac{4 r}{3}$.

Based on the equations, emitted photoelectrons from a nanoparticle is:

$N_{P E}=N_{p h} \times p$

Eq. 12

and the total number of nanoparticles $N_{N P}$ in cell slab for a given concentration, $\mathrm{C}(\mathrm{mg} / \mathrm{g})$, is obtained by:

$N_{N P}=\frac{C \times V_{\text {cell }} \times \rho_{\text {cell }}}{\frac{4}{3} \pi r^{3} \rho_{N P}}$

So, the total number of photoelectrons which are emitted from nanoparticles is:

$N_{\text {total.PE }}=N_{P E} \times N_{N P}$

and range of the emitted photoelectrons $\left(R_{T}\right)$ for a kinetic energy $\left(E_{K E}=E-E_{L-e d g e}\right)$ is given by:

$R_{T}=0.0431\left(E_{K E}+0.367\right)-0.007$

According to kinetic energy and range of emitted photoelectrons from nanoparticles, deposit energy of the photons in the cell $\left(E_{E C}\right)$ is calculated by:

$E_{E C}=\frac{2 \pi R_{T}(0.5 T)^{2}-2 \pi R_{T}\left(R_{T}-0.5 T\right)}{4 \pi R_{t}(0.5 T)^{2}} \int_{r}^{R_{T}} 3.316\left(R_{T}-x+\right.$ $0.007)^{-0.435}+0.0055\left(R_{T}-x\right)^{0.33} d x$

Eq. 16

where $\mathrm{T}$ is the thickness of the cell. 
As results total deposited energy from all emitted photoelectrons is given by:

$E_{\text {total.EC }}=E_{E C} \times N_{\text {total.PE }}$

Dose from nanoparticles is calculated by total deposited energy from nanoparticles in slab cell volume:

$D_{N P}=E_{\text {total.EC }} /\left(V_{\text {cell }} \times \rho_{\text {cell }}\right)$

Therefore, the dose enhancement factor of nanoparticles is given by:

$D E F=\frac{D_{w}+D_{N p}}{D_{w}}$

Eq. 19

\section{Results}

${ }^{125} \mathrm{I}$ and ${ }^{169} \mathrm{Yb}$ sources were simulated by MCNP code and dosimetric parameters of the sources were calculated according to TG-43 dosimetric formalism. Dose rate constant $\left(\mathrm{cGyh}^{-1} \mathrm{U}^{-1}\right)$ for both sources $\left({ }^{125} \mathrm{I}\right.$ and $\left.{ }^{169} \mathrm{Yb}\right)$ of this study and previous works (with the same source) is listed in Table 1.
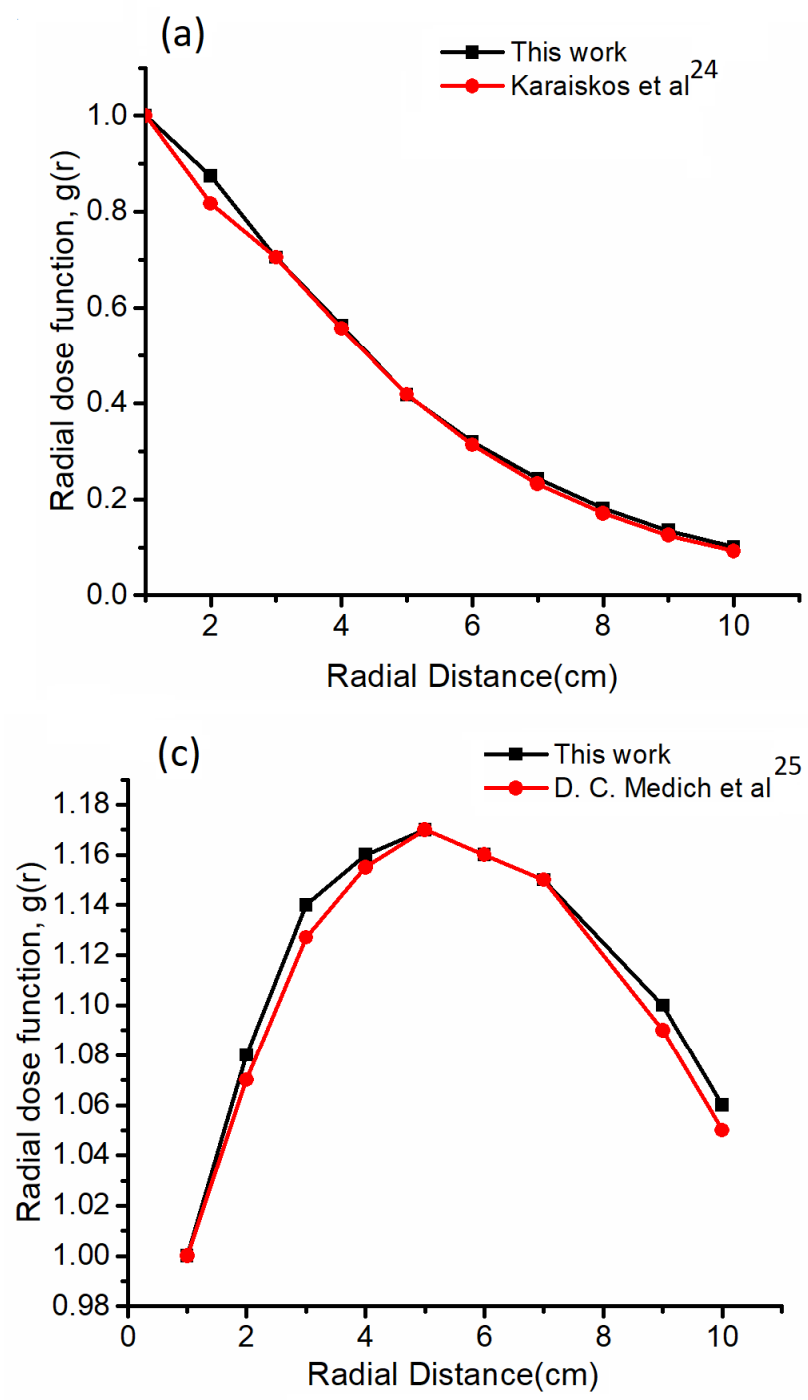

Table 1. Dose rate constant $(\Lambda)$ of the ${ }^{125} \mathrm{I}$ and ${ }^{169} \mathrm{Yb}$ brachytherapy this and previous studies.

\begin{tabular}{|c|c|c|}
\hline Author & $\Lambda\left(c_{\left.G y ~ h^{-1} U^{-1}\right)}\right.$ & Uncertainty \\
\hline This work (125-I) & 0.95 & 0.004 \\
\hline Karaiskos et al ${ }^{24}(125-\mathrm{I})$ & 0.954 & 0.005 \\
\hline This work $(169-\mathrm{Yb})$ & 1.24 & 0.05 \\
\hline D. C. Medich et al ${ }^{25}(169-Y b)$ & 1.19 & 0.03 \\
\hline
\end{tabular}

The calculated dose rate constant $(\Lambda)$ for the ${ }^{125} \mathrm{I}$ and ${ }^{169} \mathrm{Yb}$ sources was $0.95 \pm 0.004 \mathrm{cGy} \mathrm{h}^{-1} \mathrm{U}^{-1}$ and $1.24 \pm 0.05 \mathrm{cGy} \mathrm{h}^{-1}$ $\mathrm{U}^{-1}$, respectively, as it is shown in Table 1 in comparison with data of previous works, $0.954 \pm 0.005 \mathrm{cGy} \mathrm{h}^{-1} \mathrm{U}^{-1}\left({ }^{125} \mathrm{I}\right.$, SelectSeed,130.002, Karaiskos et al. [24]) and 1.19 \pm 0.03 cGy $\mathrm{h}^{-1} \mathrm{U}^{-1}\left({ }^{169} \mathrm{Yb}, 4140\right.$, Medich et al. [25]) is reasonable.

Calculated results for radial dose function, $g(r)$, (from 1 to 10 $\mathrm{cm}$ with a distance of $1 \mathrm{~cm}$ ) and the anisotropy function, $\mathrm{F}(\mathrm{r}, \theta)$ (at the radial distance of $\mathrm{r}=1 \mathrm{~cm}$ ) for the ${ }^{125} \mathrm{I}$, SelectSeed, and the ${ }^{169} \mathrm{Yb}, 4140$, sources are presented graphically in Figure 2.
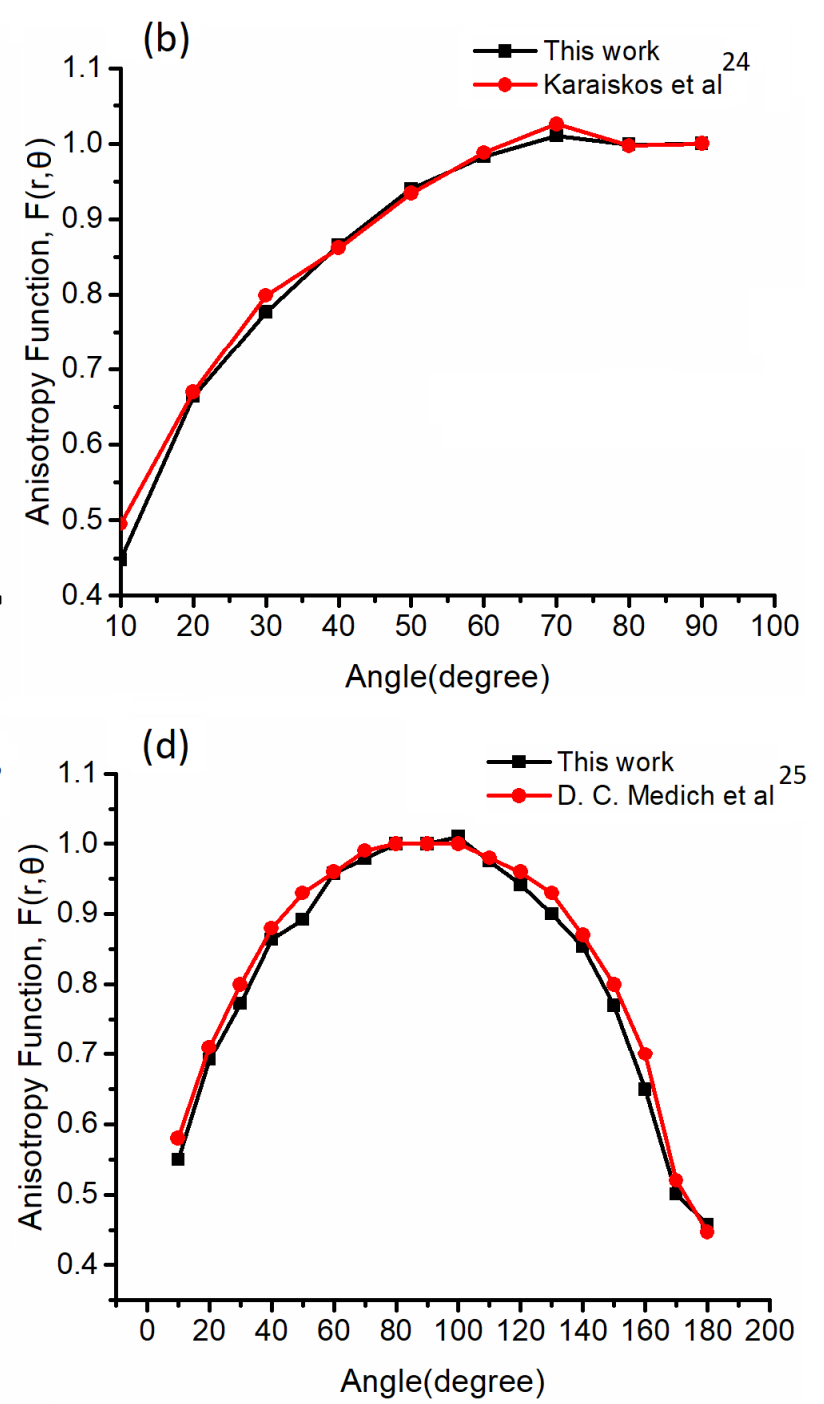

Figure 2. Radial dose function and anisotropy function of $125 \mathrm{I}$ SelectSeed $130.002(\mathrm{a}, \mathrm{b})$ and $169 \mathrm{Yb} 4041$ (c, d) brachytherapy sources from the study and previous works $[24,25]$. 
As it is clear from Figure 2, the results show a good agreement between calculated TG-43 parameters from the simulation and previous studies [24,25].

\section{Dose enhancement}

Dose enhancement factor for bismuth-based nanoparticles such as $\mathrm{Bi}, \mathrm{Bi}_{2} \mathrm{O}_{3}, \mathrm{Bi}_{2} \mathrm{~S}_{3}$, and $\mathrm{BiFeO}_{3}$ at the presence of ${ }^{125} \mathrm{I}$ and ${ }^{169} \mathrm{Yb}$ brachytherapy sources was calculated by MCNP6 code. The factor for nanoparticles with two concentrations of 10 and $20 \mathrm{mg}$ at the size of $50 \mathrm{~nm}$ and $100 \mathrm{~nm}$ for both the brachytherapy sources is shown in Figures 3, 4 and 5. Pure bismuth nanoparticle has the highest dose enhancement factor and it decreases for $\mathrm{Bi}_{2} \mathrm{O}_{3}, \mathrm{Bi}_{2} \mathrm{Se}_{3}$, and $\mathrm{BiFeO}_{3}$ respectively for both radiation sources. Figures 3, 4 and $\mathbf{5}$ show that DEF increase with concentration and size of nanoparticles. For example, DEF for $10 \mathrm{mg}$ of $100 \mathrm{~nm}$ Bi nanoparticle is 2.52 $\left({ }^{125} \mathrm{I}\right)$ and $1.5\left({ }^{169} \mathrm{Yb}\right)$ while it decreases to 2.06 and 1.37 for $50 \mathrm{~nm} \mathrm{Bi}$ nanoparticle. As shown in Figure 5 dose enhancement factor (DEF) for all the aforementioned bismuthbased nanoparticles at ${ }^{169} \mathrm{Yb}$ source is lower than DEF at ${ }^{125} \mathrm{I}$ source due to an inverse proportion of photoelectric cross section to energy.

Figure 6 shows amplification dose of bismuth-based nanoparticles for various concentration $(10 \mathrm{mg}, 20 \mathrm{mg}, 30 \mathrm{mg}$, and $40 \mathrm{mg}$ ) which is calculated by the analytical method. For analytical method same as MCNP method pure bismuth nanoparticles have highest DEF and bismuth ferrite nanoparticles have lowest DEF. we consider mono-energy 30 keV near to L-edge X-ray Absorption of bismuth.
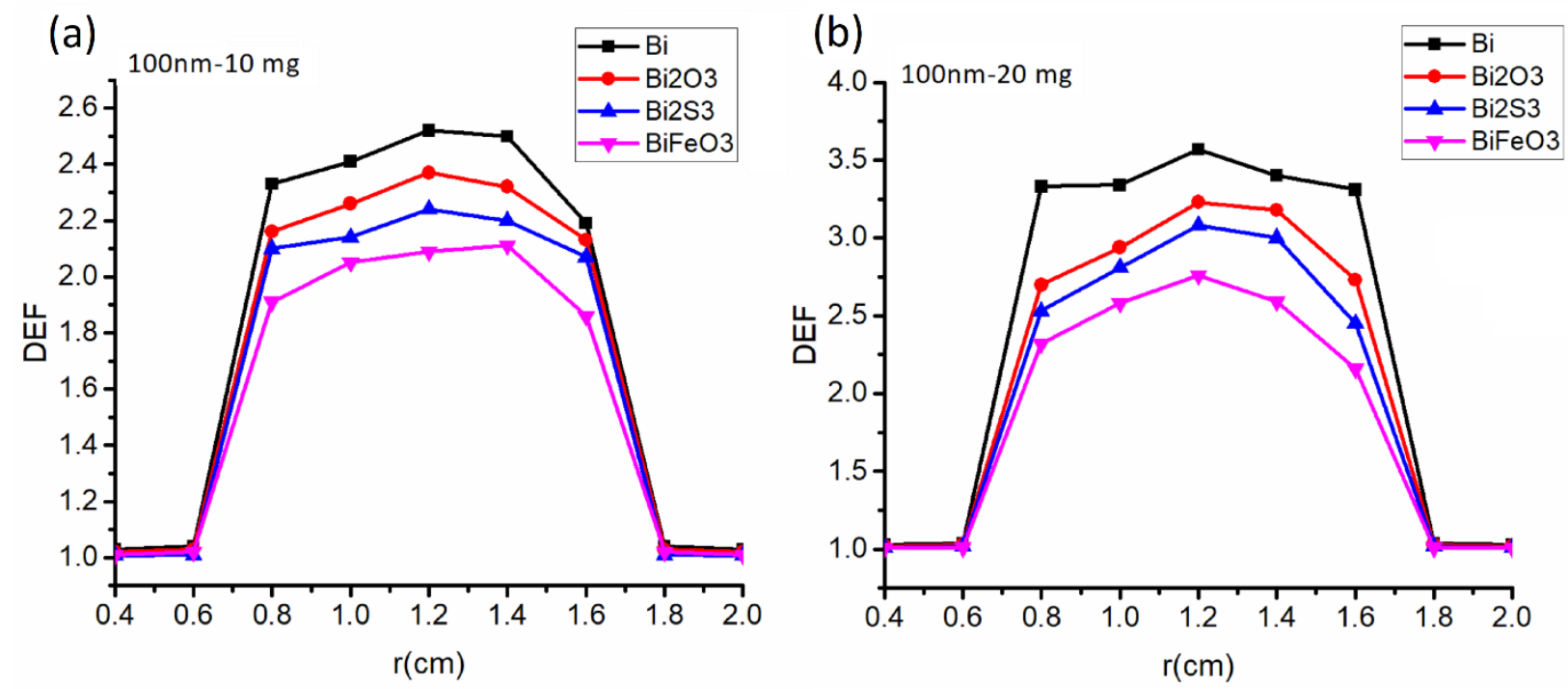

Figure 3. Monte Carlo results of dose enhancement $100 \mathrm{~nm}$ bismuth-based nanoparticles for concentrations $10 \mathrm{mg}(\mathrm{a})$ and $20 \mathrm{mg}(\mathrm{b})$ at ${ }^{125} \mathrm{I}$ low dose rate brachytherapy source.

(a)

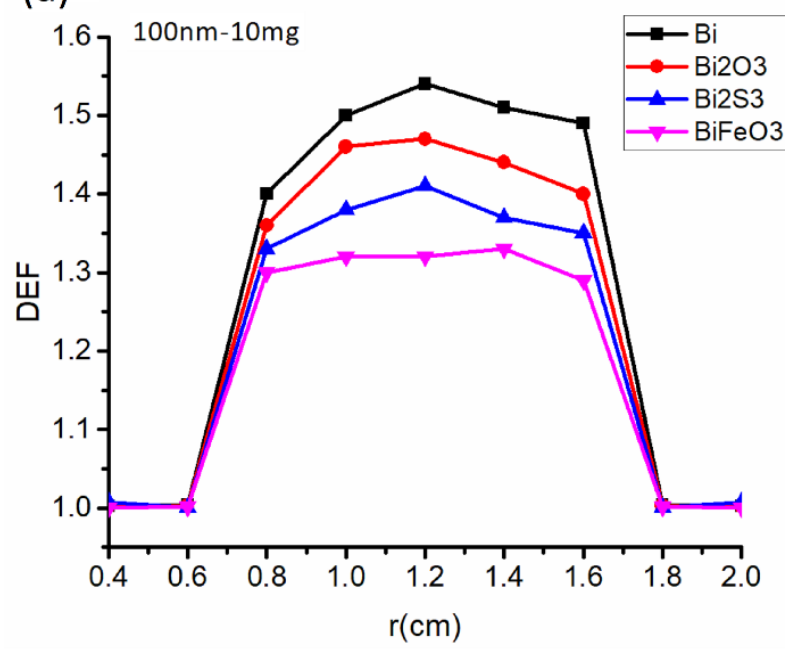

(b)

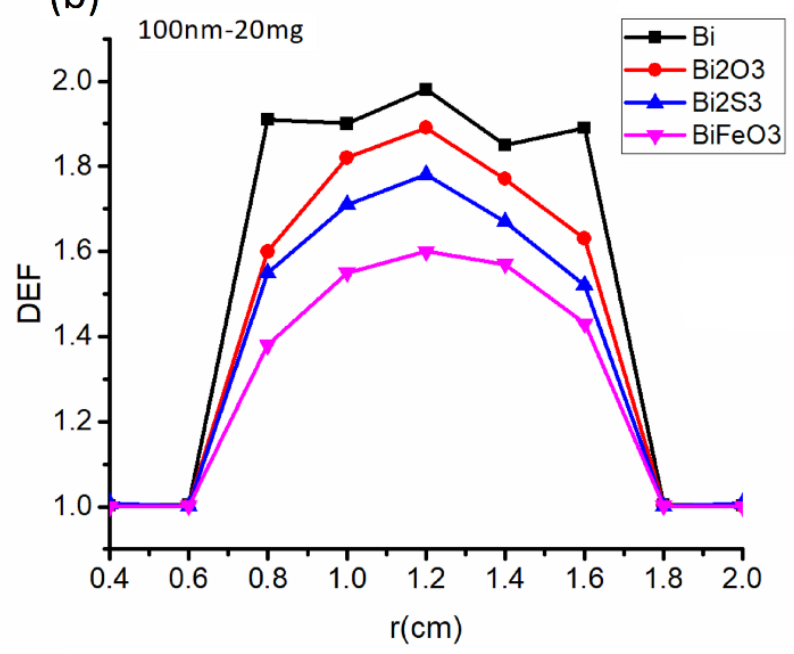

Figure 4. Monte Carlo results of dose enhancement $100 \mathrm{~nm}$ bismuth-based nanoparticles for concentrations $10 \mathrm{mg}$ (a) and $20 \mathrm{mg}(\mathrm{b})$ at ${ }^{169} \mathrm{Yb}$ high dose rate brachytherapy source. 
(a)

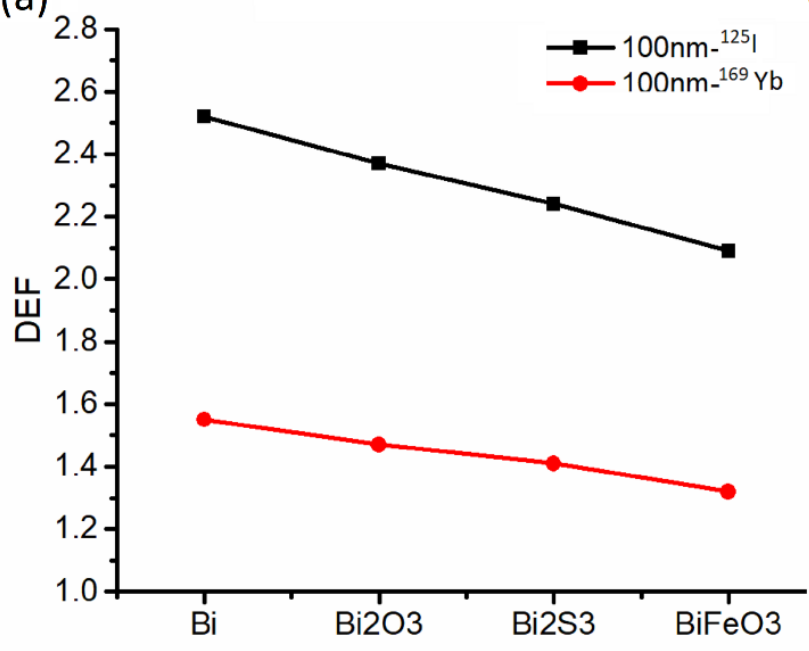

(b)

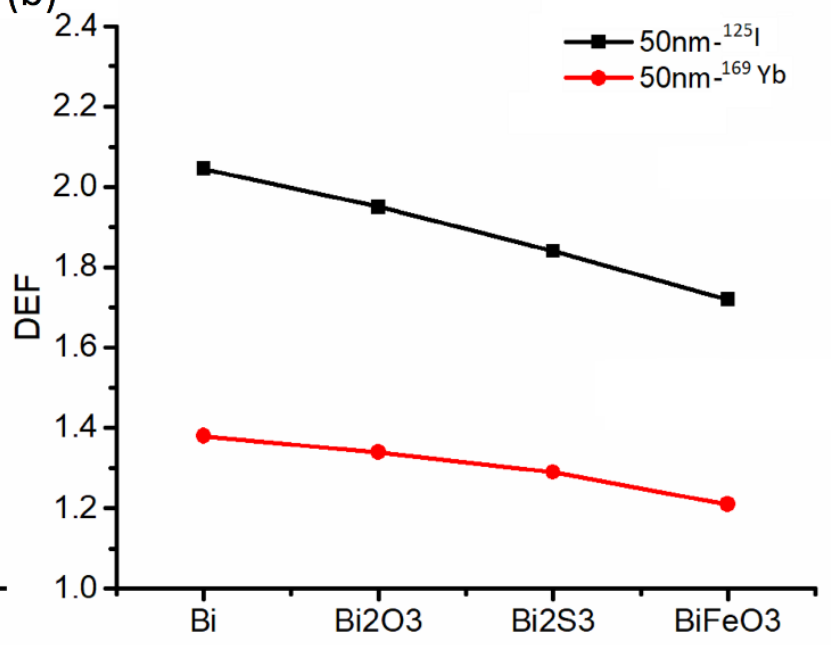

Figure 5. Monte Carlo results of dose enhancement bismuth-based nanoparticles size of $100 \mathrm{~nm}$ (a) and $50 \mathrm{~nm}(\mathrm{~b})$ at ${ }^{125} \mathrm{I}$ and ${ }^{169} \mathrm{Yb}$ brachytherapy source.

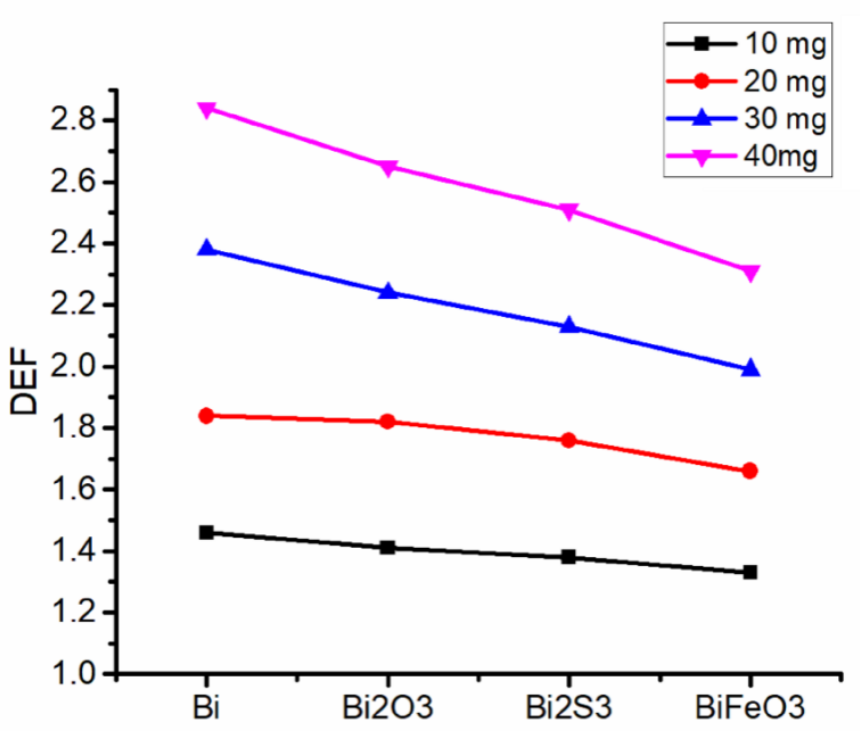

Figure 6. Analytic results of dose enhancement various concentrations bismuth-based nanoparticles at $30 \mathrm{keV}$ monoenergy.

\section{Discussion}

Possessing a high atomic number and cost-effective advantages, bismuth nanoparticle deserves thorough studies to show bismuth-based nanoparticles as a promising candidate in radiotherapy for cancer treatment. In this work, we simulated two brachytherapy source ${ }^{125} \mathrm{I}$ and ${ }^{169} \mathrm{Yb}$ for calculating the effect of the bismuth-based nanoparticles on radiation dose amplification by MCNP code. Moreover, we compared the dose enhancement factor of various bismuth-based nanoparticles with an analytical method for mono-energetic photon sources. As it is clear from both analytical and MCNP code methods, pure bismuth has highest dose enhancement and bismuth ferrite is lowest among the aforementioned bismuth based-nanoparticles. However, bismuth ferrite nanoparticle has lowest DEF, the nanoparticle has magnetic and liner optical property which can employ for hyperthermia and photodynamic therapy. Moreover, the $\mathrm{BiFeO}_{3}$ nanoparticle may have the ability to apply for magnetic resonance image (MRI), and computed tomography $(\mathrm{CT})$ as multimodal contrast agent due to $\mathrm{Fe}(\mathrm{Z}=56)$ as a magnetic particle $(\mathrm{MRI})$ and $\mathrm{Bi}(\mathrm{Z}=82)$ with high photoelectric absorption (CT imaging) [6].

However, in this study, we have not decided to compare results of both methods of simulation (analytic and MCNP code) due to differences in conditions and radiation source, dose enhancement factors calculated of an analytical method is lower than MCNP simulation. Analytical simulation has some limitation [26], it doesn't consider photoelectron interactions of neighboring bismuth nanoparticles while Monte Carlo simulation involves interactions of neighboring nanoparticles. Monte Carlo simulation accounts all photoelectric, Auger electron and Compton photon and electron, while the analytic method just considers photoelectrons coefficient absorption.

\section{Conclusions}

The dose enhancement effect of bismuth-based nanoparticles ( $\mathrm{Bi}, \mathrm{Bi}_{2} \mathrm{O}_{3}, \mathrm{Bi}_{2} \mathrm{~S}_{3}$, and $\mathrm{BiFeO}_{3}$ ) was compared by Monte Carlo (MCNP-Code) and analytic simulation. Based on results of simulation and analytical methods pure bismuth nanoparticles and bismuth oxide have the highest dose enhancement factor in comparison with bismuth sulfide and bismuth ferrite. DEF increases with increasing concentration and size of nanoparticles. Results of analytical and Monte Carlo simulation express the physical aspect of radiation dose amplification from bismuth-based nanoparticles. Further experimental studies need to carry out in which the nanoparticles are considered as a physical radiosensitizer to improve the efficiency of radiation therapy. 


\section{References}

[1] Hwang C, Kim JM, Kim J. Influence of concentration, nanoparticle size, beam energy, and material on dose enhancement in radiation therapy. J Radiat Res. 2017;58:405-411.

[2] Hatano Y, Katsumura Y, Mozumder A. Charged Particle and Photon Interactions with Matter: Recent Advances, Applications and Interfaces. CRC Press, Boca Raton, 2010.

[3] McMahon SJ, Hyland WB, Muir MF, et al. Biological consequences of nanoscale energy deposition near irradiated heavy atom nanoparticles. Sci Rep. 2011;1:18.

[4] Khoo AM, Cho SH, Reynoso FJ, et al. Radiosensitization of Prostate Cancers In Vitro and In Vivo to Erbium-filtered Orthovoltage X-rays Using Actively Targeted Gold Nanoparticles. Scientific Reports. 2017;7:18044.

[5] Sung W, Schuemann J. Energy optimization in gold nanoparticle enhanced radiation therapy. Phys Med Biol. 2018;63(13):135001.

[6] Rajaee A, Wensheng X, Zhao L, et al. Multifunctional Bismuth Ferrite Nanoparticles as Magnetic Localized Dose Enhancement in Radiotherapy and Imaging. J Biomed Nanotechnol. 2018;14(6):1159-1168.

[7] Kuncic Z, Lacombe S. Nanoparticle radio-enhancement: principles, progress and application to cancer treatment. Phys Med Biol. 2018;63(2):27.

[8] Porcel E, Liehn S, Remita H, et al. Platinum nanoparticles: a promising material for future cancer therapy? Nanotechnology. 2010;21(8):85103.

[9] Ma M, Huang Y, Chen H, et al. Bi2S3-embedded mesoporous silica nanoparticles for efficient drug delivery and interstitial radiotherapy sensitization Biomaterials. 2015;37:447-455.

[10] Deng J, Xu S, Hu W, et al. Tumor targeted, stealthy and degradable bismuth nanoparticles for enhanced X-ray radiation therapy of breast cancer. Biomaterials. 2018;154:24-33.

[11] Yao MH, Ma M, Chen Y, et al. Multifunctional Bi2S3/PLGA nanocapsule for combined HIFU/radiation therapy. Biomaterials. 2014;35(28):8197-8205.

[12] Xie H, Li Z, Sun Z, et al. Metabolizable Ultrathin Bi2Se3 Nanosheets in Imaging-Guided Photothermal Therapy. Small. 2016;12(30): 4136-4145.

[13] Gorbach SL. Bismuth therapy in gastrointestinal-diseases. Gastroenterology. 1990;99(3):863-875.

[14] Bravo LE, Realpe JL, Campo C, et al. Effects of acid suppression and bismuth medications on the performance of diagnostic tests for Helicobacter pylori infection. Am J Gastroenterol. 1999;94(9):2380-2383.

[15] Wei B, Zhang X, Zhang C, et al. Facile Synthesis of Uniform-Sized Bismuth Nanoparticles for CT Visualization of Gastrointestinal Tract in Vivo. Acs Applied Mater Interfaces. 2016;8(20):12720-12726.

[16] Bi H, He F, Dong Y, et al. Bismuth Nanoparticles with "Light" Property Served as a Multifunctional Probe for X-ray Computed Tomography and Fluorescence Imaging. Chem Mat. 2018;30(10):3301-3307.

[17] Ai K, Liu Y, Liu J, . Large-Scale Synthesis of Bi2S3 Nanodots as a Contrast Agent for In Vivo X-ray Computed Tomography Imaging. Adv Mater. 2011;9(23):4886-4891.

[18] Cheng X, Yong Y, Dai Y, et al. Enhanced Radiotherapy using Bismuth Sulfide Nanoagents Combined with Photo-thermal Treatment. Theranostics. 2017;7(17):4087-4098.

[19] Liu J, Zheng X, Gu Z, et al. Bismuth sulfide nanorods as a precision nanomedicine for in vivo multimodal imaging-guided photothermal therapy of tumor. Nanomedicine-Nanotechnology Biology and Medicine. 2016;12(2):486-487.

[20] Taha E, Djouider F, Banoqitah E. Monte Carlo simulations for dose enhancement in cancer treatment using bismuth oxide nanoparticles implanted in brain soft tissue. Australas Phys Eng Sci Med. 2018;41(2):363-370.

[21] Du F, Lou J, Jiang R, et al. Hyaluronic acid-functionalized bismuth oxide nanoparticles for computed tomography imaging-guided radiotherapy of tumor. Int J Nanomedicine. 2017;12:5973-5992.

[22] Stewart C, Konstantinov K, McKinnon S, et al. First proof of bismuth oxide nanoparticles as efficient radiosensitisers on highly radioresistant cancer cells. Phys Med. 2016;32(11):1444-1452.

[23] Hossain M, Su M. Nanoparticle Location and Material-Dependent Dose Enhancement in X-ray Radiation Therapy. J Phys Chem C. 2012;116(43):23047-23052.

[24] Karaiskos P, Papagiannis P, Sakelliou L, et al. Monte Carlo dosimetry of the selectSeed I-125 interstitial brachytherapy seed.Med Phys. 2011;28(8):1753-1760.

[25] Medich DC, Tries MA, Munro JJ. Monte Carlo characterization of an ytterbium-169 high dose rate brachytherapy source with analysis of statistical uncertainty. Med Phys. 2006;33(1):163-172.

[26] Paro AD, Hossain M, Webster TJ, Su M. Monte Carlo and analytic simulations in nanoparticle-enhanced radiation therapy. Int J Nanomedicine. 2016;11:4735-4741.

[27] Ngwa W, Makrigiorgos GM, Berbeco RI. Applying gold nanoparticles as tumor-vascular disrupting agents during brachytherapy: estimation of endothelial dose enhancement. Phys Med Biol. 2010;55(21):6533-6548. 